\title{
Multimodal Reduction of Elastic Vibrations in Plate Structure using Super Absorbent Polymer Beads
}

\author{
Takahiro Tomioka ${ }^{\mathrm{a}, *}$, Karen Minamisawa ${ }^{\mathrm{b}}$ \\ aDepartment of Mechanical Engineering, Faculty of Systems, Science and Technology, Akita Prefectural University. Email:tomioka@akita-pu.ac.jp \\ ${ }^{b}$ Former Department of Machine Intelligence and Systems Engineering, Faculty of Systems, Science and Technology, Akita Prefectural University.
}

\begin{abstract}
This paper deals with multimodal reduction of structural elastic vibrations. Super absorbent polymer beads (SAP beads) have been introduced as a simple damping device inspired by the multimodal vibration reduction effect by passengers on railway vehicles. A series of vibration measurement tests using a 1:10 scale model of railway vehicle floor structure (model underframe) was carried out. The SAP beads which are sold commonly as water retention agent were stacked in a container and applied to the model underframe. From the experiments, multimodal vibration reduction effects have been demonstrated. A drastic difference has been observed when water was added together with SAP beads. To investigate the basic mechanism of the damping effect obtained by the experiments, an analytical model, which consists of multiple masses that are supported at an angle to each other, and its simplified model was proposed and numerical studies were conducted. Some specific combinations of the mass, spring, and damping elements in the model could express the experimental results well, and it has been estimated from the numerical results that each SAP layer act as an un-uniform subsystem.

Keywords: Elastic vibration; damping; multimodal vibration reduction; vibration analysis; viscoelastic material; super absorbent polymer
\end{abstract}

\section{Introduction}

The elastic vibrations that occur during machine operation tend to become conspicuous particularly in large and/or light-weighted mechanical systems such as the bodies of aircraft or railway vehicles. Generally, several elastic vibration modes are dominant at the same time in those structures, so simultaneous vibration reduction for multiple elastic modes (multimodal vibration reduction) is required to improve the quality and performance of the mechanical system such as maintaining ride quality. Of course, from an industrial application perspective, simple and cost-effective devices are needed. Dynamic vibration absorber (DVA) is a common and popular passive damping device with a simple configuration and established optimal design methods [1].

For railway vehicles, the idea of utilizing underfloor equipment as a DVA has been studied for a long time. Ishikawa and Sato [2] conducted a running test by applying elastically supported mass which imitated underfloor equipment and showed the reduction of the first mode of bending vibration of the carbody. Gong et al. [3] studied to use several kinds of equipment underneath the floor and on the roof as DVAs for different elastic modes

${ }^{\star}$ Corresponding author. Tel.: +81-184-27-2131

84-4, Tsuchiya-ebinokuchi, Yurihonjo, Akita, Japan, 015-0055 of vibration by finite element analysis. However, since an ordinary DVA is a single-mode vibration absorber, a corresponding number of DVAs is necessary for multimodal vibration reduction.

Recently, one of the authors and his colleagues reported passengers' effect on the vibration of light-weighted railway vehicles [4], [5]. Figure 1(a) shows the acceleration power spectrum densities (PSDs) measured on the floor at the window side of the longitudinal center of a Shinkansen train during running at $270 \mathrm{~km} / \mathrm{h}$ [4]. The peak observed around $10.5 \mathrm{~Hz}$ is considered corresponding to vertical elastic vibration mode(s) of the carbody. It can be seen that the peak value is reduced by increasing the number of passengers, whereas the change in the peak frequency is very small. The vibration reduction effect is also observed on the other peaks at least up to $20 \mathrm{~Hz}$. Figure 1(b) compares the PSDs of the carbody loaded with 51 distributed onboard passengers and 5100 $\mathrm{kg}$ of iron blocks. Relative to the unloaded carbody, the peak around $10.5 \mathrm{~Hz}$ altered differently under passenger and iron block loadings; iron blocks reduced the peak frequency but exerted little effect on the peak value, whereas passengers induced a small frequency shift and a large reduction in the peak value. They show an additional damping effect by passengers, rather than an added mass effect. And the additional damping works on the multiple 


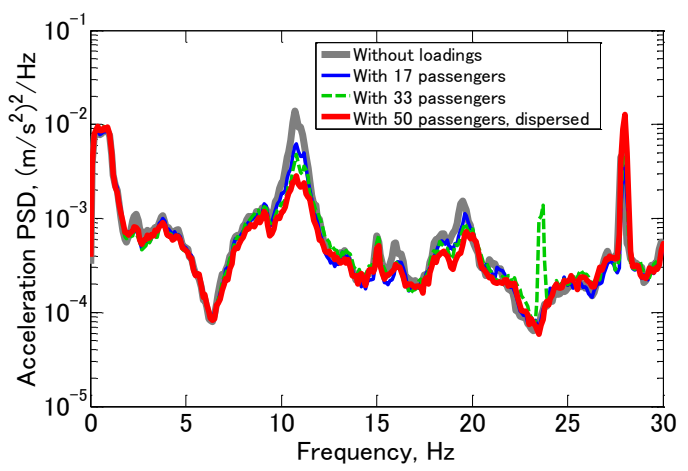

(a) Effect of the number of passengers

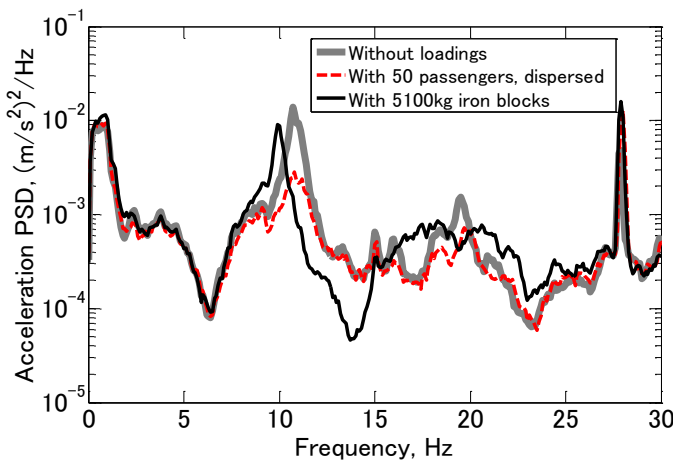

(b) Comparison of PSDs loaded with 50 passengers and $5100 \mathrm{~kg}$ of iron blocks on the floor

Figure 1. Acceleration PSDs of a Shinkansen measured during running at $270 \mathrm{~km} / \mathrm{h}$ [4]. (At longitudinal center, window side on the floor)

elastic vibrations of a running carbody, not on a single mode.

These results suggest that, if the passengers' damping capabilities can be mimicked appropriately, it is expected to realize simple and effective passive vibration reduction devices. Some hints for it are: a human body has many natural frequencies corresponding to the motions of each organ or part, and a human body vibrates in every direction as a viscoelastic body. Based on these ideas, some trials have been carried out such as mounting flexible polyethylene tanks filled with some different kinds of liquid [5] or applying elastic torus filled with water [6], [7]. Their damping performances were confirmed by the excitation tests using actual railway vehicles. Those trials are considered utilizing elastic deformations of the applied objects as DVA.

In this study, super absorbent polymer beads (called SAP beads hereafter) are introduced as a multimodal vibration reduction device considering the viscoelastic characteristics of humans. Vibration measurement tests using a 1:10 scale model of railway vehicle floor structure were conducted, and the damping performance of SAP beads was investigated. Also, an analytical model and its simplified model were proposed to study the basic damping mechanism.

\section{Setups for the Experimental Studies}

\subsection{Test structure and vibration measurement equipment}

Figure 2 shows the elastic plate-like structure used in vibration testing in this study. This is a 1:10 scale model of railway vehicle floor structure, so it is called "model underframe" in this paper. The model underframe, which is made of stainless steel, is consisting of a thin plate reinforced by many beams with U-shaped cross-sections arranged like a ladder. Its size is length $\mathrm{x}$ width $\mathrm{x}$ thickness $=2000 \mathrm{~mm} \times 310 \mathrm{~mm} \times 10 \mathrm{~mm}$ and the mass is $10.5 \mathrm{~kg}$. The model underframe was supported by springs (BRIDGESTONE Hybrid Air Damper) at four points like usual railway vehicle carbody and excited using an electro-dynamic exciter (Asahi WaveMaker SL0505) attached at the front end. The response vibration acceleration was measured by piezoelectric accelerometers (PCB 352C65). The excitation force was also measured using a load cell (PCB 208C02). The detailed measurement points on the model underframe are illustrated in Fig. 3. A total of 21 acceleration measurement points was arranged to check the natural modes of the elastic vibration, and the acceleration measured at the center of the model underframe (point $\mathrm{f4c}$ ) was used to evaluate the vibration reduction effect by SAP beads as described later.

The electrodynamic exciter was driven by a bandlimited random signal (a random signal applied by bandpass filter with cut-off frequencies of 10 and $250 \mathrm{~Hz}$ ), and the duration of excitation was $60 \mathrm{~s}$. The measured acceleration and force signals were recorded as digital data with a sampling frequency of $2048 \mathrm{~Hz}$.

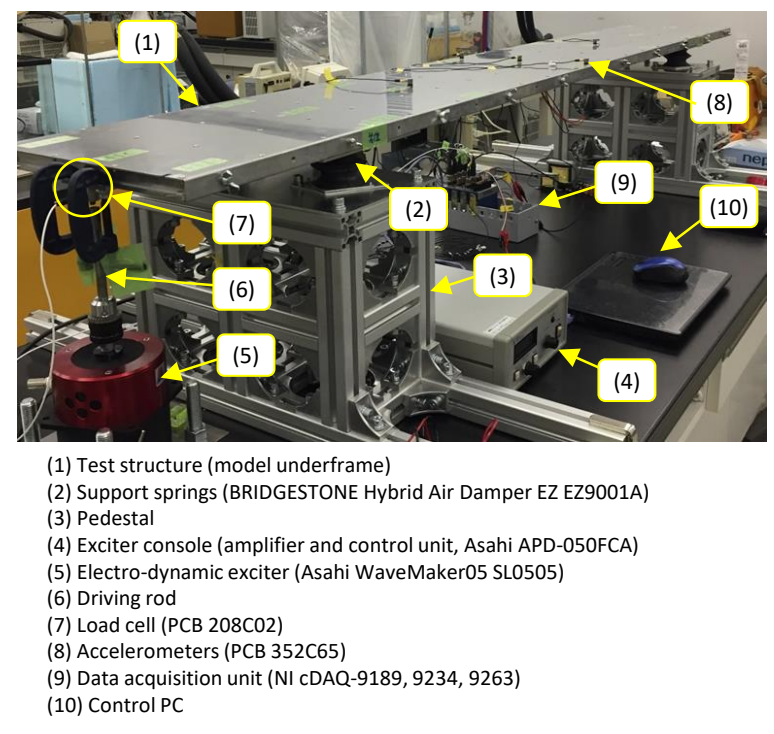

Figure 2. The test structure and the vibration measurement equipment

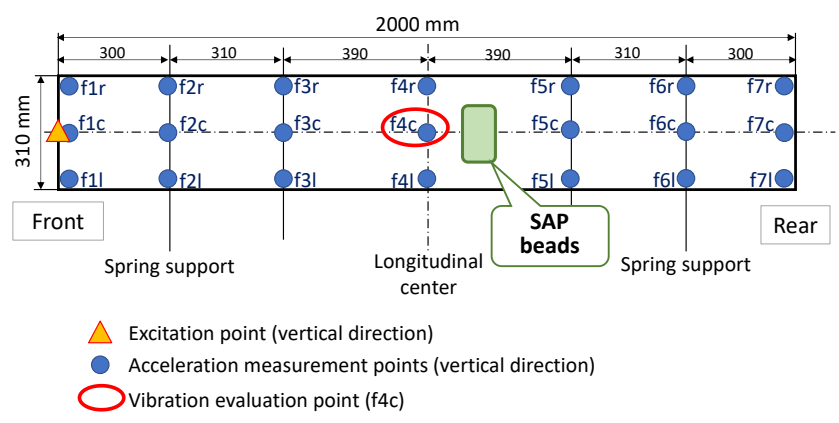

Figure 3. Measurement and excitation points on the model underframe 


\subsection{Loading conditions using SAP beads}

In this study, which is a basic study for the multimodal vibration reduction of the model underframe, SAP beads filled in a container were chosen and examined as a simple multimodal damping device. Figure 4 shows the SAP bead and containers used here. The SAP beads are sold commonly as a water retention agent (substituting natural soil) or fragrance control material, and very easy to purchase. The SAP beads with a size of approximately 15 $\mathrm{mm}$ in diameter after soaking were used here. As for the containers of SAP beads, two types made of different materials, plastic (relatively flexible) and stainless steel (SUS; almost rigid), were used. Both of them are common food containers.

The loading conditions for SAP beads in this study are listed in Table 1 together with photographs. Case 1 compares the difference of loading amount of SAP beads in the same container: Case 2 is used to check the container's flexibility upon the damping effect: and Case 3 investigates the effects of water addition. The container filled with SAP beads was attached to the model underframe with thin and strong double-sided tape (NICHIBAN NICETACK NW-K10) at the position shown in Fig. 3.

\section{Results of Vibration Measurement Tests}

\subsection{Test results for the single test underframe}

The test results for the single test underframe (without any loadings) are described in this subsection to show its original vibration characteristics.

Figure 5 shows the natural vibration modes of the test underframe itself identified by the measured acceleration

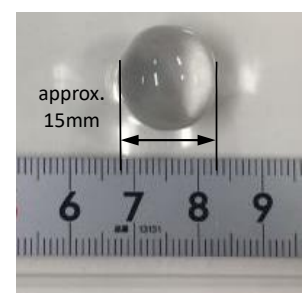

(a) A piece of SAP bead

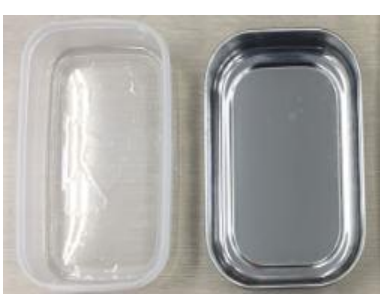

(b) Containers of the SAP beads Left: plastic (flexible, $45 \mathrm{~g}$ ),

Right: stainless steel (SUS, almost rigid, $58 \mathrm{~g}$ )
Figure 4. SAP bead and its containers used in the experiments

Table 1. Loading conditions for the experiments

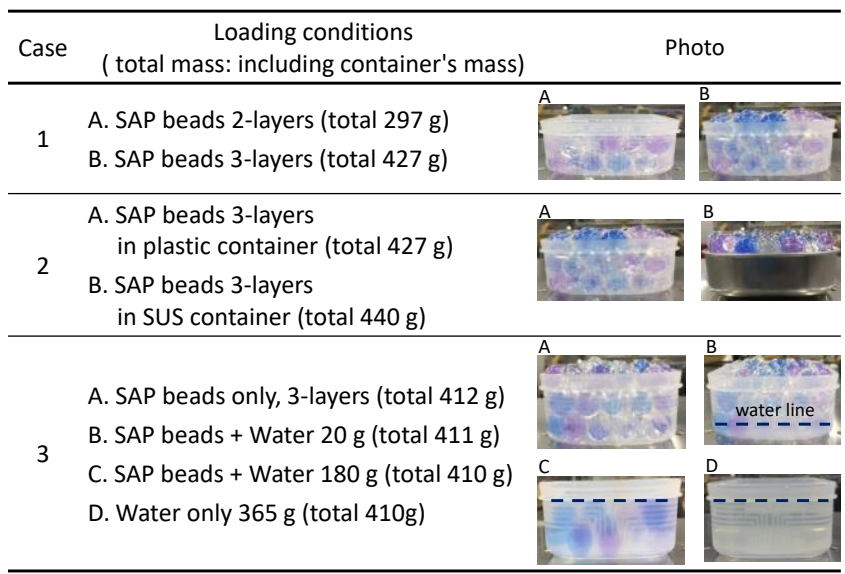

data. The modal analysis was carried out by applying the technique based on an ARX (Auto-Regressive eXogenous) model [8]. The thick and thin lines respectively express the deformed and undeformed shape, and the figures with "Hz" are natural frequencies. Five bending modes were obtained below $250 \mathrm{~Hz}$, and no elastic modes with torsional deformation were identified since the excitation point (f1c) was near their nodes. The first bending mode (Fig. 5(a)) is commonly observed in actual railway vehicles.

Figure 6 shows the frequency response functions (FRFs) of acceleration measured at point $\mathrm{f} 4 \mathrm{c}$ versus excitation force. Five prominent peaks corresponding to the bending modes shown in Fig. 5 can be observed. Two different curves express the data measured on different days to confirm the repeatability of the experiment under the same conditions.

\subsection{Damping capabilities of SAP beads}

The damping capability of SAP beads is investigated through the acceleration FRF. The conditions of excitation and FRF evaluation are the same as in Fig. 6.

At first, a comparison was made when different amounts of SAP beads were applied. Figure 7 shows the measured FRFs under the loading condition of Case 1. The gray, blue and red lines show without SAP beads, with 2layers SAP beads (Case 1A) and with 3-layers SAP beads (Case 1B), respectively. Peak values tend to be reduced as SAP beads are applied, at least with the ones corresponding to the $1 \mathrm{st}, 2 \mathrm{nd}$, and 4 th bending modes. Also, the difference between Case 1A and 1B is observed

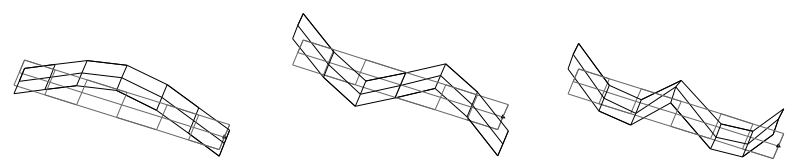

$\begin{array}{lll}\text { (a) } 1 \text { st bending }(19.0 \mathrm{~Hz}) & \text { (b) 2nd bending }(67.0 \mathrm{~Hz}) & \text { (c) } 3 \mathrm{rd} \text { bending }(125.2 \mathrm{~Hz})\end{array}$
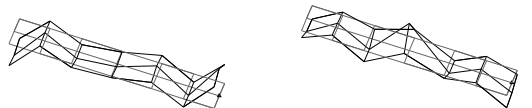

$\begin{array}{ll}\text { (d) } 4 \text { th bending }(188.2 \mathrm{~Hz}) & \text { (e) } 5 \text { th bending }(233.1 \mathrm{~Hz})\end{array}$

Figure 5. Natural vibration modes of the model underframe identified by the excitation test (without loadings)

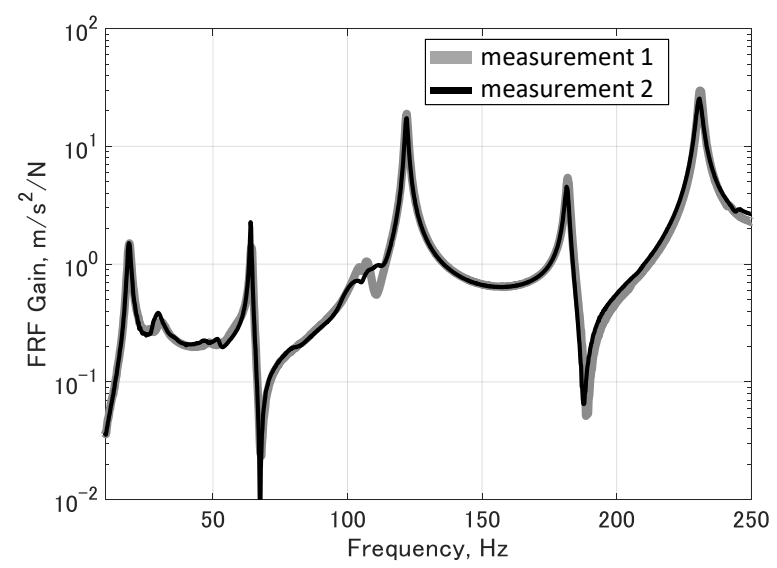

Figure 6. Measured acceleration FRFs versus excitation force at point $\mathrm{f} 4 \mathrm{c}$. (Without loadings; comparison of the data measured on different days) 


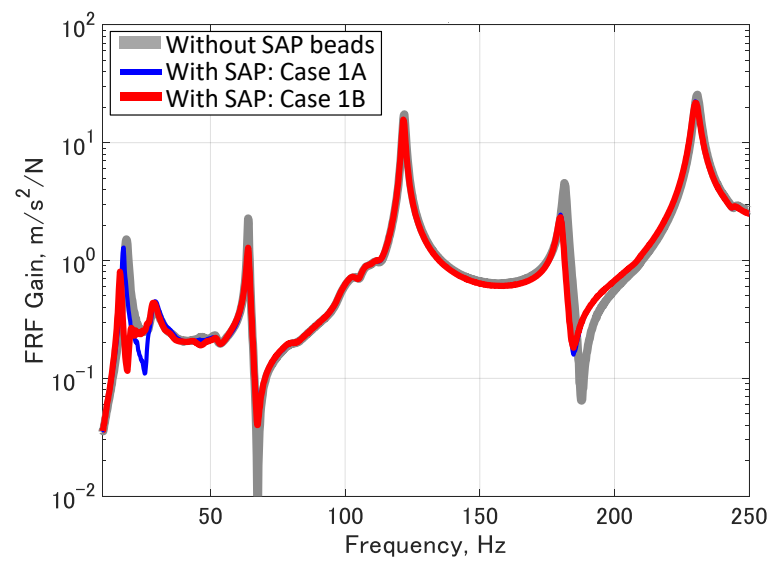

Figure 7. Measured acceleration FRFs versus excitation force at point $\mathrm{f} 4 \mathrm{c}$. (Case 1: effect of amount of SAP beads)

only for the peak near $19 \mathrm{~Hz}$. Figure 8 shows an enlarged view of Fig. 7. The peak shifts towards lower frequency as the amount of SAP beads increases. Each curve with SAP beads also has a trough whose frequency shifts in the same way as the peak.

The vibration reduction by SAP beads seems similar to the DVA effect, particularly about the 1st bending mode (near $19 \mathrm{~Hz}$ ). If it is so, the mass of SAP beads should work as DVA together with some spring elements. To check whether the container's flexibility act as the spring element, the comparison using different kinds of containers was conducted. Figure 9 shows the results of putting the same amount of SAP beads ( $382 \mathrm{~g}$ ) in different containers. The blue and red lines show the results for Case 2A (flexible plastic container) and 2B (rigid SUS container), respectively. These FRF curves are nearly overlapping, indicating that the container's flexibility does not act as a spring element for the DVA effect by SAP beads, at least up to $250 \mathrm{~Hz}$.

Figure 10 shows the results for Case 3. A drastic reduction in the higher frequency region can be observed when water was added. On the other hand, as shown in Fig. 11 , the effect by adding water is not so large on the peak around $19 \mathrm{~Hz}$. These data indicate that the mechanism of the vibration reduction effect by SAP beads may be different in low and high-frequency regions.

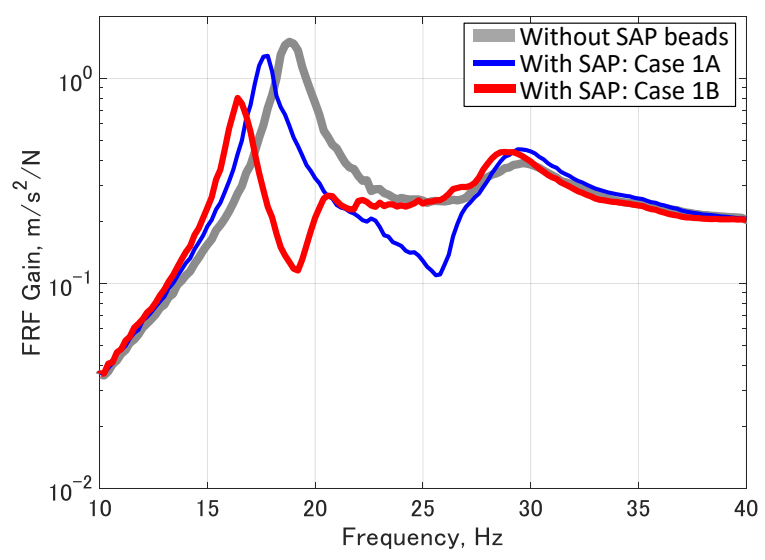

Figure 8. Enlarged view of Fig. 7

\section{Numerical Studies with Simple Analytical Models}

\subsection{Vibration analysis model for the test structure with SAP beads}

Multimodal vibration reduction by SAP beads have been observed through the experiments as described in the former section. Some interesting results were obtained such as phenomena similar to a DVA (Figs. 7, 8) and changes by adding water (Figs. 10, 11). The latter one showed a different tendency in the low and high-frequency regions.

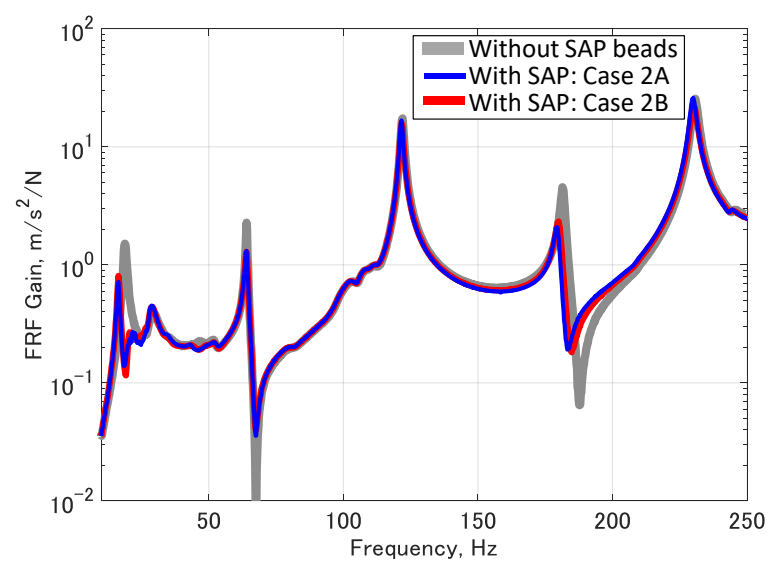

Figure 9. Measured acceleration FRFs versus excitation force at point $\mathrm{f} 4 \mathrm{c}$. (Case 2: effect of container's flexibility)

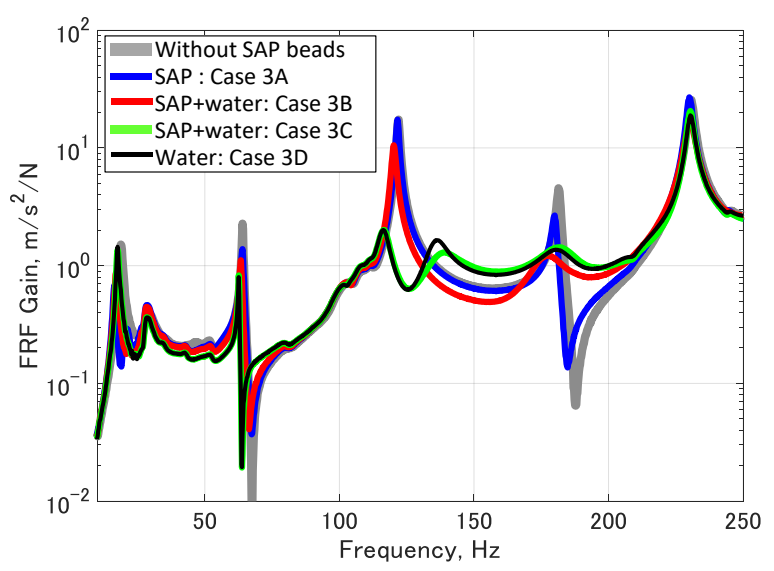

Figure 10. Measured acceleration FRFs versus excitation force at point $\mathrm{f} 4 \mathrm{c}$. (Case 3 : effect of adding water)

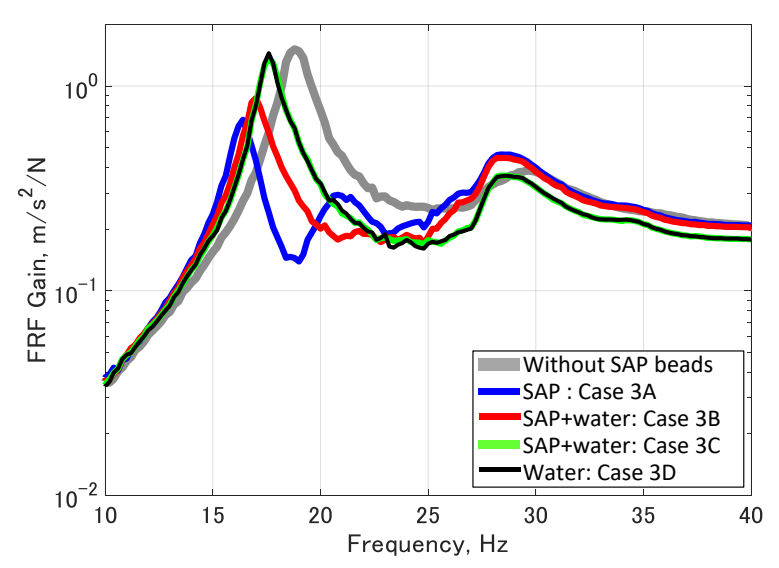

Figure 11. Enlarged view of Fig. 10 
To investigate the basic mechanism of the damping capability by SAP beads, some simple analytical models are introduced here, and numerical calculations are conducted. From the experimental results, characteristic changes were observed in the measured FRF curves at the peak near $19 \mathrm{~Hz}$. The proposed analytical models target the frequency region where this mode is dominant.

Figure 12 shows the proposed vibration analysis models. The mass $m_{0}$ denotes the main system (the model underframe, here), $m_{p q}(p=1,2,3, q=1,2$ for $p=1,3, q=1,2,3$ for $p=2$ ) express the mass of SAP beads of $p$-th layer, $x_{0}$ and $x_{p q}$ denote displacement of $m_{0}$ and $m_{p q}$, respectively, $F(t)$ is the harmonic excitation force applied to $m_{0}$ concerning time $t$ with circular frequency $\omega$, and $j$ is the imaginary unit. $\tilde{k}_{p q}$ denotes equivalent complex spring to support $m_{p q}$ consisting of ordinary spring $k_{p q}$ and viscous damping $c_{p q}$. Note this expression is supposing the analysis in the frequency domain for the steady-state response against harmonic excitation at $\omega$. Also, since each SAP bead is supported each other in oblique direction rather than directly above (see the photos in Table 1), the supporting angles $\theta_{p q}$ are taken into account in the supporting springs $\tilde{k}_{p q}$. In the numerical study described later, the basic mechanism of the damping ability is investigated by adjusting these parameters. In this paper, the parameter adjustment is carried out by trial and error method comparing the numerical and experimental results.

The kinetic and potential energies for the system with a 3-layer SAP model can be written as follows.

$$
\begin{aligned}
T & =\frac{1}{2} m_{0} \dot{x}_{0}^{2}+\frac{1}{2} m_{11} \dot{x}_{11}{ }^{2}+\frac{1}{2} m_{12} \dot{x}_{12}^{2} \\
& +\frac{1}{2} m_{21} \dot{x}_{21}{ }^{2}+\frac{1}{2} m_{22} \dot{x}_{22}{ }^{2}+\frac{1}{2} m_{23} \dot{x}_{23}{ }^{2} \\
& +\frac{1}{2} m_{31} \dot{x}_{31}{ }^{2}+\frac{1}{2} m_{32} \dot{x}_{32}{ }^{2}
\end{aligned}
$$

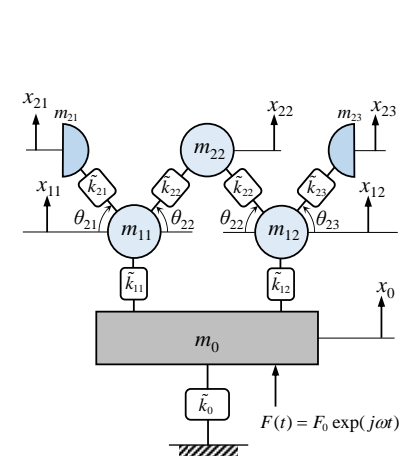

(a) With 2-layer SAP model

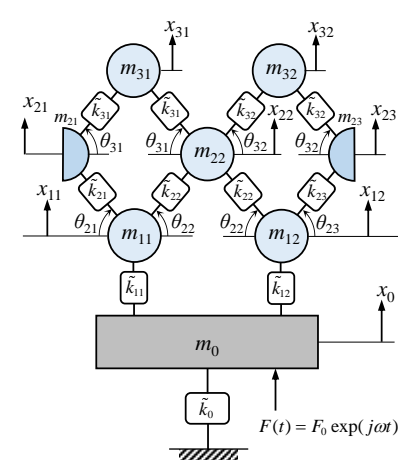

(b) With 3-layer SAP model

$$
\begin{gathered}
\underbrace{\perp}_{\tilde{k}_{p q}}=k_{p q}{\text { 岁 } c_{p q}}_{\tilde{k}_{p q}}=k_{p q}+j \omega c_{p q}
\end{gathered}
$$

(c) Equivalent spring model

Figure 12. Proposed vibration model of test structure with 2-layer and 3-layer SAP models

$$
\begin{aligned}
V & =\frac{1}{2} \tilde{k}_{0} x_{0}^{2}+\frac{1}{2} \tilde{k}_{11}\left(x_{11}-x_{0}\right)^{2}+\frac{1}{2} \tilde{k}_{12}\left(x_{12}-x_{0}\right)^{2} \\
& +\frac{1}{2} \tilde{k}_{21} \sin ^{2} \theta_{21}\left(x_{21}-x_{11}\right)^{2}+\frac{1}{2} \tilde{k}_{22} \sin ^{2} \theta_{22}\left(x_{22}-x_{11}\right)^{2} \\
& +\frac{1}{2} \tilde{k}_{22} \sin ^{2} \theta_{22}\left(x_{22}-x_{12}\right)^{2}+\frac{1}{2} \tilde{k}_{23} \sin ^{2} \theta_{23}\left(x_{23}-x_{12}\right)^{2} \\
& +\frac{1}{2} \tilde{k}_{31} \sin ^{2} \theta_{31}\left(x_{31}-x_{21}\right)^{2}+\frac{1}{2} \tilde{k}_{31} \sin ^{2} \theta_{31}\left(x_{31}-x_{22}\right)^{2} \\
& +\frac{1}{2} \tilde{k}_{32} \sin ^{2} \theta_{32}\left(x_{32}-x_{22}\right)^{2}+\frac{1}{2} \tilde{k}_{32} \sin ^{2} \theta_{32}\left(x_{32}-x_{23}\right)^{2}
\end{aligned}
$$

where $T$ and $V$ indicate the kinetic and the potential energies, respectively, dot (') expresses derivative with respect to $t$. By applying following Lagrange's equation,

$$
\frac{d}{d t}\left(\frac{\partial T}{\partial \dot{\mathbf{x}}}\right)+\frac{\partial V}{\partial \mathbf{x}}=\mathbf{F}
$$

the equations of motion can be obtained as follows.

$$
\mathbf{M} \ddot{\mathbf{x}}+\tilde{\mathbf{K}} \mathbf{x}=\mathbf{F}
$$

where

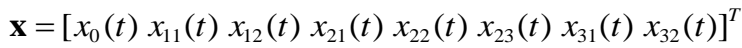

$$
\begin{aligned}
& \mathbf{F}=\left[\begin{array}{llllllll}
F(t) & 0 & 0 & 0 & 0 & 0 & 0 & 0
\end{array}\right]^{T}
\end{aligned}
$$

and $\mathbf{M}$ and $\tilde{\mathbf{K}}$ are the mass and the complex equivalent stiffness matrices, respectively. Considering steady-state response to harmonic excitation, $\mathbf{x}$ and $\mathbf{F}$ can be written as,

$$
\begin{aligned}
& \mathbf{x}=\left[\begin{array}{llllllll}
X_{0} & X_{11} & X_{12} & X_{21} & X_{22} & X_{23} & X_{31} & X_{32}
\end{array}\right]^{T} e^{j \omega t}=\mathbf{X} e^{j \omega t} \\
& \mathbf{F}=\left[\begin{array}{llllllll}
F_{0} & 0 & 0 & 0 & 0 & 0 & 0 & 0
\end{array}\right]^{T} e^{j \omega t}=\mathbf{F}_{0} e^{j \omega t}
\end{aligned}
$$

where $\mathbf{X}$ and $\mathbf{F}_{0}$ express the time-independent components of the response displacement and the input force. By solving the Eq. (4) at specified $\omega$, the response at the frequency versus input force magnitude can be calculated and $\mathbf{X}$ expresses the frequency response function (FRF) of displacement when unit input force $\left(F_{0}=1\right)$ is applied. The obtained displacement FRF vector has eight elements (eight degrees of freedom; 8DOF) corresponding to the model with the 3-layer SAP model shown in Fig. 12(b). For the case with a 2-layer SAP model, the abovementioned formulation procedure is the same, just by omitting the values for the third layer (the values with $p=3)$. To compare the numerical results with measured ones in acceleration FRF, $\left|\omega^{2} \mathbf{X}(\omega)\right|$ for unit input force will be calculated in the next subsection.

These analysis models seem to have interesting features by the effects of supporting angle, mass distribution, the balance of supporting springs, etc., however, for simplicity, the following assumptions are introduced in this paper.

$$
\left\{\begin{array}{l}
m_{11}=m_{12}, m_{21}=m_{23}=m_{22} / 2, m_{31}=m_{32}, \\
\tilde{k}_{11}=\tilde{k}_{12}, \tilde{k}_{21}=\tilde{k}_{22}=\tilde{k}_{23}, \tilde{k}_{31}=\tilde{k}_{32}, \\
\theta_{21}=\theta_{22}=\theta_{23}, \theta_{31}=\theta_{32}
\end{array}\right.
$$




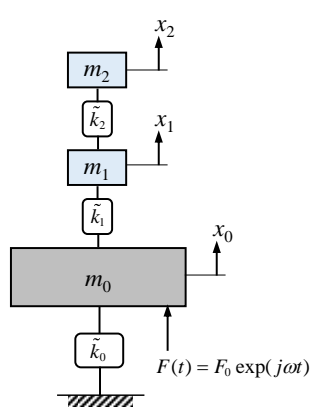

(a) With 2DOF SAP model

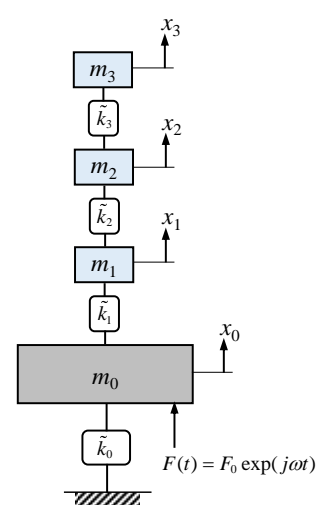

(b) With 3DOF SAP model
Figure 13. Simplified vibration model of test structure with 2DOF and 3DOF SAP models equivalent to Fig. 12 under the assumptions of Eq. (5)

Under these assumptions, those models become equivalent to the 3DOF (with 2DOF SAP model, for the case with 2-layer SAP model) and 4DOF (with 3DOF SAP model, for the case with 3-layer SAP model) simple models as shown in Fig. 13. And the elements of the equations of motion (4) can be reduced as follows.

$$
\begin{aligned}
\mathbf{M} & =\left[\begin{array}{cccc}
m_{0} & & & 0 \\
& m_{1} & & \\
& & m_{2} & \\
0 & & m_{3}
\end{array}\right], \\
\tilde{\mathbf{K}} & =\left[\begin{array}{cccc}
\tilde{k}_{0}+\tilde{k}_{1} & -\tilde{k}_{1} & 0 & 0 \\
-\tilde{k}_{1} & \tilde{k}_{1}+\tilde{k}_{2} & -\tilde{k}_{2} & 0 \\
0 & -\tilde{k}_{2} & \tilde{k}_{2}+\tilde{k}_{3} & -\tilde{k}_{3} \\
0 & 0 & -\tilde{k}_{3} & \tilde{k}_{3}
\end{array}\right]
\end{aligned}
$$

There are following relations between these two models.

$$
\left\{\begin{array}{l}
m_{11}+m_{12}=2 m_{11} \equiv m_{1}, \\
m_{21}+m_{22}+m_{23}=2 m_{22} \equiv m_{2}, \\
m_{31}+m_{32}=2 m_{31} \equiv m_{3}, \\
\tilde{k}_{11}+\tilde{k}_{12}=2 \tilde{k}_{11} \equiv \tilde{k}_{1}, \\
\tilde{k}_{21} \sin ^{2} \theta_{21}+2 \tilde{k}_{22} \sin ^{2} \theta_{22}+\tilde{k}_{23} \sin ^{2} \theta_{23}=4 \tilde{k}_{22} \sin ^{2} \theta_{22} \equiv \tilde{k}_{2}, \\
2 \tilde{k}_{31} \sin ^{2} \theta_{31}+2 \tilde{k}_{32} \sin ^{2} \theta_{32}=4 \tilde{k}_{32} \sin ^{2} \theta_{32} \equiv \tilde{k}_{3}
\end{array}\right.
$$

\subsection{Numerical results and discussions}

Numerical calculations were carried out to investigate the basic mechanism of the damping effects by SAP beads. The calculations were focusing on the peak around $19 \mathrm{~Hz}$ observed in the experiments. Its peak height seems not so prominent according to the measurement results shown in section 3; however, this peak is corresponding to the first bending mode of the model underframe which is one of the major targets to be reduced in actual railway vehicles. Besides, the peak height is strongly influenced by the excitation conditions, so the first bending mode may be more prominent under other excitation conditions.

The parameters for the main component were chosen as shown in Table 2 by referring to the actual condition of the model underframe. For SAP beads, the parameters listed in Table 3 were applied. The masses of the SAP were decided as $0.3 \mathrm{~kg}$ and $0.42 \mathrm{~kg}$ for SAP 2-layer and 3-layer cases, respectively. The spring and damping coefficients were determined heuristically by comparing the calculated acceleration FRFs with experimental results. The values in Table 3 are for the models in Fig. 13. The parameter values for the corresponding (equivalent) model shown in Fig. 12 are also listed in Tables A1-A6 in Appendix A.

Figure 14 shows the numerical results of acceleration FRFs of $m_{0}$ versus input force when the subsystem with two different 2DOF systems was applied. This calculation was intended to check the applicability of the 2DOF subsystem model in the case for the 3-layer SAP is applied. The spring constants $k_{1}=8.4 \times 10^{3} \mathrm{~N} / \mathrm{m}$ and $k_{2}=25.2 \times 10^{3}$ $\mathrm{N} / \mathrm{m}$ were selected for both the $2 \mathrm{DOF}$ SAP model. These are respectively equivalent to $k_{11}=4.2 \times 10^{3} \mathrm{~N} / \mathrm{m}$ and $k_{22}=2 k_{11}$ in the model of Fig. 12(a) under the assumption of Eq. (5), with all supporting angles are set to 60 degrees. (The detailed parameter values for the model in Fig. 12(a) are listed in Tables A1 and A2.) The masses were adjusted to express two and three-layer SAP cases, respectively. By using these parameters, the 2DOF SAP models have natural frequencies of $25.506 \mathrm{~Hz}$ (the 2-layer case) and $21.556 \mathrm{~Hz}$ (the 3-layer case), respectively. Comparing these FRF calculation results with the corresponding experimental results shown in Fig. 8, it can be found that the blue line agrees well with each other. So it is considered that the measured result with 2-layers of SAP beads can be represented by the 2DOF SAP model, and the trough frequency observed in the FRF corresponds to one of the natural frequencies of the additional system. On the other hand, some differences are observed in the red

\begin{tabular}{|c|c|c|c|c|c|c|}
\hline $\begin{array}{l}\text { Intended } \\
\text { experimental } \\
\text { condition }\end{array}$ & Case $1 \mathrm{~A}$ & Case1B & Case1B & $\begin{array}{l}\text { Case } 1 \mathrm{~B} \\
\text { Case } 3 \mathrm{~A}\end{array}$ & Case $3 B$ & Case $3 \mathrm{C}$ \\
\hline variable unit model & $\begin{array}{l}\text { SAP 2DOF } \\
\text { (Fig. 13(a)) }\end{array}$ & $\begin{array}{l}\text { SAP 2DOF } \\
\text { (Fig. 13(a)) }\end{array}$ & $\begin{array}{l}\text { SAP 3DOF } \\
\text { (Fig. 13(b)) }\end{array}$ & $\begin{array}{l}\text { SAP 3DOF } \\
\text { (Fig. 13(b)) }\end{array}$ & $\begin{array}{l}\text { SAP 3DOF } \\
\text { (Fig. 13(b)) }\end{array}$ & $\begin{array}{l}\text { SAP 3DOF } \\
\text { (Fig. 13(b)) }\end{array}$ \\
\hline$m_{1}$ & 0.15 & 0.21 & 0.15 & 0.195 & 0.195 & 0.195 \\
\hline $\begin{array}{ll}k_{1} & \mathrm{~N} / \mathrm{m} \\
\end{array}$ & $8.4 \times 10^{3}$ & $\leftarrow$ & $\leftarrow$ & $\leftarrow$ & $\leftarrow$ & $12.0 \times 10^{3}$ \\
\hline $\begin{array}{ll}c_{1} & \mathrm{Ns} / \mathrm{m}\end{array}$ & 3.55 & 4.20 & $\leftarrow$ & 4.05 & 10.12 & 12.09 \\
\hline$\zeta_{1}$ & 0.05 & $\leftarrow$ & $\leftarrow$ & $\leftarrow$ & 0.125 & $\leftarrow$ \\
\hline$m_{2}$ & 0.15 & 0.21 & 0.15 & 0.195 & 0.195 & 0.195 \\
\hline $\begin{array}{ll}k_{2} & \mathrm{~N} / \mathrm{m}\end{array}$ & $25.2 \times 10^{3}$ & $\leftarrow$ & $12.6 \times 10^{3}$ & $\leftarrow$ & $\leftarrow$ & $25.2 \times 10^{4}$ \\
\hline $\begin{array}{ll}c_{2} & \mathrm{Ns} / \mathrm{m}\end{array}$ & 7.53 & 8.91 & 5.32 & 8.59 & $\leftarrow$ & 27.15 \\
\hline$\zeta_{2}$ & 0.05 & $\leftarrow$ & $\leftarrow$ & $\leftarrow$ & $\leftarrow$ & $\leftarrow$ \\
\hline$m_{3}$ & - & - & 0.12 & 0.03 & $\leftarrow$ & $\leftarrow$ \\
\hline $\begin{array}{ll}k_{3} & \mathrm{~N} / \mathrm{m} \\
\end{array}$ & - & - & $12.6 \times 10^{3}$ & 540 & 5400 & $\leftarrow$ \\
\hline $\begin{array}{ll}c_{3} & \mathrm{Ns} / \mathrm{m}\end{array}$ & - & - & 4.76 & 0.493 & 1.56 & $\leftarrow$ \\
\hline$\zeta_{3}$ & - & - & 0.05 & 0.05 & $\leftarrow$ & $\leftarrow$ \\
\hline $\begin{array}{l}\begin{array}{c}\text { Total } \\
\text { additional } \\
\text { mass }\end{array} \\
\mathrm{kg}\end{array}$ & 0.3 & 0.42 & 0.42 & 0.42 & 0.42 & 0.42 \\
\hline Numerical result & $\begin{array}{l}\text { Fig. 14-16 } \\
\text { (blue line) }\end{array}$ & $\begin{array}{l}\text { Fig. } 14 \\
\text { (redline) }\end{array}$ & $\begin{array}{c}\text { Fig. } 15 \\
\text { (redline) }\end{array}$ & $\begin{array}{c}\text { Fig. 16 } \\
\text { (red line) } \\
\text { Fig. 17 } \\
\text { (blue line) }\end{array}$ & $\begin{array}{c}\text { Fig. 17 } \\
\text { (reăline) }\end{array}$ & $\begin{array}{l}\text { Fig. } 17 \\
\text { (green line) }\end{array}$ \\
\hline Description & $\begin{array}{l}\text { 2DOF SAP } \\
\text { model for } \\
\text { SAP 2-layer } \\
\text { Case }\end{array}$ & $\begin{array}{l}\text { Applicability } \\
\text { check of the } \\
2 D O F \text { SAP } \\
\text { model for } \\
\text { 3-layer Case }\end{array}$ & $\begin{array}{l}\text { Nearly } \\
\text { uniform } \\
\text { distribution } \\
\text { of } m_{p q} \text { and } k_{p q}\end{array}$ & $\begin{array}{l}\text { Un-uniform } \\
\text { distribution } \\
\text { of } m_{p q} \text { and } k_{p q}\end{array}$ & $\begin{array}{l}\text { Effect of wate } \\
\text { adjusting the } \\
\text { model }\end{array}$ & $\begin{array}{l}\text { addition by } \\
\text { BDOF SAP }\end{array}$ \\
\hline
\end{tabular}
line such as; in Fig. 14, the peak around $17 \mathrm{~Hz}$ is higher than Fig. 8 and there is another peak around $23 \mathrm{~Hz}$ which doesn't exist in Fig. 8. These may indicate the 2DOF SAP

Table 2. Calculation parameters for the main component. (Assuming the 1st bending mode of the model underframe)

\begin{tabular}{ccc}
\hline variable & unit & value \\
\hline$m_{0}$ & $\mathrm{~kg}$ & 10 \\
\hline$k_{0}$ & $\mathrm{~N} / \mathrm{m}$ & $14.2517 \times 10^{4}$ \\
\hline$c_{0}$ & $\mathrm{Ns} / \mathrm{m}$ & 71.6284 \\
\hline$\zeta_{0}$ & - & 0.03 \\
\hline$f_{0}$ & $\mathrm{~Hz}$ & 19.0 \\
\hline
\end{tabular}

Table 3. Calculation parameters for the 2DOF and 3DOF SAP models 
model is inappropriate to represent the SAP 3-layers case. Note that the small peak around $30 \mathrm{~Hz}$ seen in the experimental results is supposed to a rigid mode that the model underframe vibrates over supporting springs without elastic deformation, which is out of focus of the numerical models here.

The red line in Fig. 15 shows a result when the 3DOF SAP model is used to represent the 3-layer SAP case. The gray and blue lines are the same as Fig. 14. On the red line, the spring constants for $k_{1}$ is equal to the 2DOF SAP model, and $k_{2}=k_{3}=12.6 \times 10^{3} \mathrm{~N} / \mathrm{m}$ are applied here, which correspond to $k_{22}=k_{31}=k_{11}=4.2 \times 10^{3} \mathrm{~N} / \mathrm{m}$ in Fig. 12(b). The assumptions in Eq. (5) and all supporting angles are 60 degrees are used again. (See Appendix Table A3.) The mass values are set $m_{1}=m_{2}$ and $m_{3}=0.8 m_{2}$. These 3DOF SAP model settings are intended to presume the elasticity and mass density of SAP are nearly uniform, however rather large disagreement with Fig. 8 is observed over the 2DOF model in Fig. 14.

Figure 16 shows the case that the 3DOF SAP model is used and un-uniform distributions are assumed for $m_{p q}$ and $k_{p q}$ with $m_{11}=m_{22}=0.0975 \mathrm{~kg}, m_{32}=0.015 \mathrm{~kg}, k_{11}=4.2 \times 10^{3}$ $\mathrm{N} / \mathrm{m}, \quad k_{22}=2 k_{11}, \quad k_{31}=180 \mathrm{~N} / \mathrm{m}$. Other parameters and assumptions are the same as Figs. 14 and 15. (See Appendix Table A4.) The red curve in this figure seems well to express the experimental result shown in Fig. 8. This may suggest that the top layer of SAP beads stacked

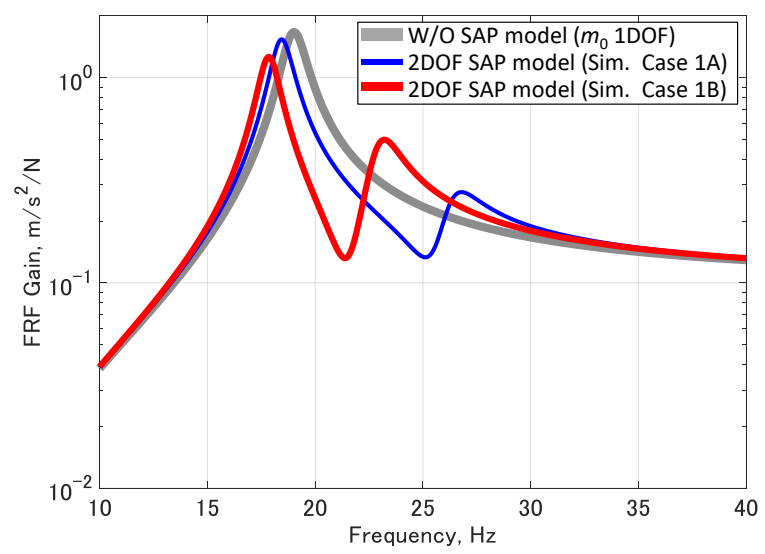

Figure 14. Numerical results of acceleration FRF intended to simulate the experiments for Case 1. (2DOF SAP model is applied for the Case 1B)

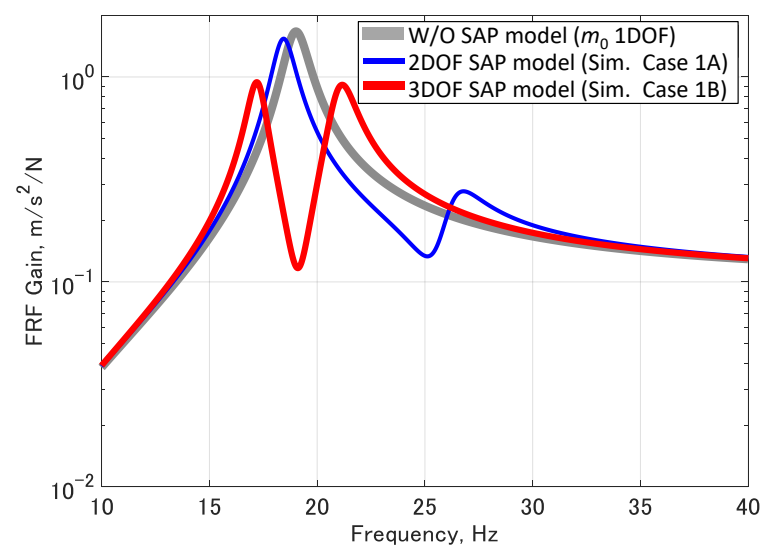

Figure 15. Numerical results of acceleration FRF intended to simulate the experiments for Case 1. (3DOF SAP model with nearly uniform distributions of $m_{p q}$ and $k_{p q}$ are applied for the Case 1B)

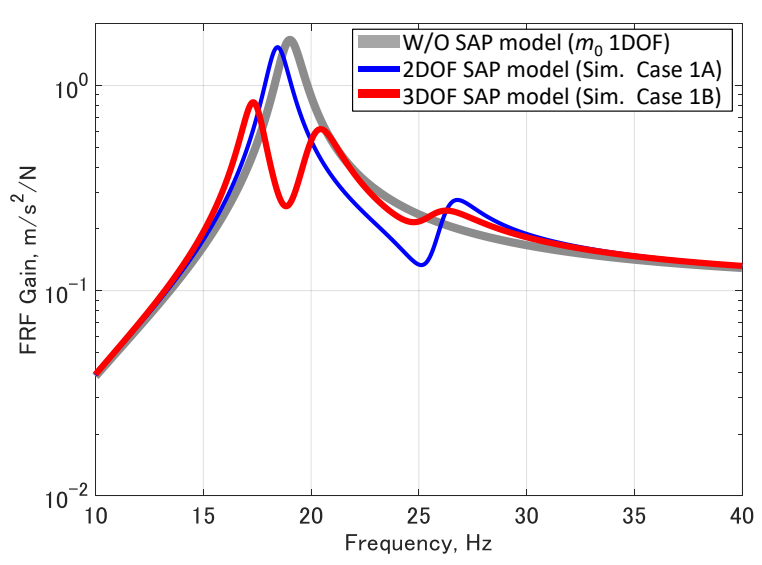

Figure 16. Numerical results of acceleration FRF intended to simulate the experiments for Case 1. (3DOF SAP model with un-uniform distributions of $m_{p q}$ and $k_{p q}$ are applied for the Case 1B)

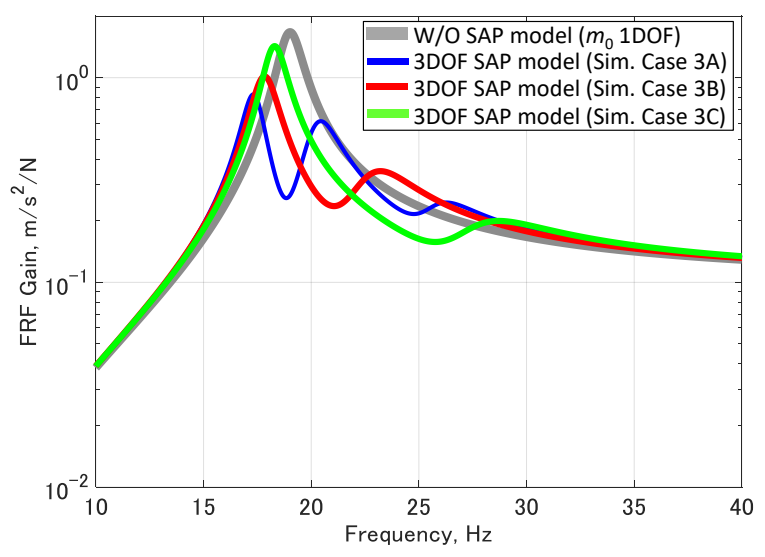

Figure 17. Numerical results of acceleration FRF intended to simulate the experiments for Case 3

in more than 3-layers act as smaller mass and spring elements than the layers below. This may also relate to the stacking condition, that is, as shown in Table 1, the top layer beads were loosely surrounded by the container in the experiments. In the red line, there is a trough near 25 $\mathrm{Hz}$. This is caused by the DVA effect of the motion of the 3DOF SAP model, where $m_{1}$ and $m_{2}$ are in phase, and $m_{3}$ is out of phase, according to the numerical result.

The numerical results by adjusting the 2nd and 3rd layer of the 3DOF SAP model intended to simulate the effect of water addition are shown in Fig. 17. The red line in this figure was applied the 10 times value in $k_{3}$ and the 2.5 times in $\zeta_{1}$, respectively than the 3-layer SAP model (blue line; which is the same with the red line in Fig. 16). In the green line, 20 times value was applied in $k_{2}$ and about 1.4 times in $k_{1}$. By comparing them with the experimental result shown in Fig. 10, the tendency of the peak change seems well agree. This may mean the added water effects equivalent to enlarge the spring constants of the 3 rd and 2nd layers greatly. The values for water-added conditions for the corresponding model in Fig. 12(b) are shown in Tables A5 and A6.

Since the analytical model used here was very simple, further investigations will be needed to understand the detailed damping mechanisms by SAP beads and water. However, some interesting hints about them have been obtained through the numerical study. 


\section{Conclusions}

In this study, to realize multimodal reduction of elastic vibrations in mechanical systems, super absorbent polymer beads (SAP beads) have been introduced as a simple damping device inspired by the multimodal vibration reduction effect by passengers on railway vehicles. A series of vibration measurement tests using a 1:10 scale model of railway vehicle floor structure (model underframe) was carried out. The SAP beads which are sold commonly were stacked in ordinal food container and applied to the model underframe. Also, an analytical model consisting of multiple masses supported at an angle to each other and its simplified model were proposed and numerical calculations were conducted to investigate the damping mechanisms. The results obtained in this work are summarized as follows.

- SAP beads have multimodal vibration reduction ability on the elastic vibration of the model underframe.

- The container's flexibility doesn't affect the damping effect at least up to $250 \mathrm{~Hz}$ for the experimental condition in this study. This means the damping ability comes from the viscoelastic characteristics of SAP beads themselves.

- A drastic reduction in higher frequency region can be observed when water was added together with SAP beads, indicating the vibration reduction mechanism may be different in low and high-frequency regions.

- According to the numerical investigation, it has found that some specific combinations of the mass, spring, and damping elements in the proposed analytical model could express the experimental results well and the basic mechanism of the damping effect for the lower frequency region is the DVA effect by SAP beads. Also, each SAP layer is estimated to act as an un-uniform subsystem for the cases with 3-layer SAP beads and with water.

\section{Acknowledgements}

This work was supported by JSPS KAKENHI Grant Number JP18K04024.

\section{References}

[1] J. P. Den Hartog, Mechanical Vibrations, 3rd ed. McGraw-Hill Book Company, 1947.

[2] R. Ishikawa and Y. Sato, "Decrease of Vehicle Body Bending Vibration by Dynamic Damper," in Proceedings of the 68th JSME Spring Annual Meeting, 1991, vol. C, pp. 531-533. (in Japanese)

[3] D. Gong, J. Zhou, W. Sun, Y. Sun, and X. Zhanghui, "Method of Multi-mode Vibration Control for the Carbody of High-speed Electric Multiple Unit Trains," J. Sound Vib., vol. 404, pp. 94-111, 2017.

[4] T. Tomioka and T. Takigami, "Experimental and Numerical Study on the Effect due to Passengers on Flexural Vibrations in Railway Vehicle Carbodies," J. Sound Vib., vol. 343, pp. 1-19, 2015.

[5] T. Tomioka, T. Takigami, and K. Aida, "Experimental Investigations on the Damping Effect due to Passengers on Flexural Vibrations of Railway Vehicle Carbody and Basic Studies on the Mimicry of the Effect with Simple Substitutions," Veh. Syst. Dyn., vol. 55, pp. 995-1011, 2017.

[6] T. Tomioka, S. Tachikawa, and Y. Akiyama, "Development of Torus-shaped Elastic Body as a Vibration Absorber for Flexural Vibration in Railway Vehicle Carbody and Its Experimental Validation Using Commuter-type Vehicle," Mech. Eng. J., vol. 4, 2017.

[7] T. Tomioka, S. Tachikawa, Y. Akiyama, and K. Aida, "Reduction of Flexural Vibration of Railway Vehicle Carbody by Using Elastic Torus (Validation of Vibration Reduction Effect Using Actual Railway Vehicle and Numerical Investigations on the Vibration Reduction Mechanism)," Trans. JSME, vol. 83, pp. 16-00342, 2017.

[8] T. Tomioka, T. Takigami, and K. Aida, "Modal Analysis of Railway Vehicle Carbodies Using a Linear Prediction Model," $J$. Syst. Des. Dyn., vol. 3, pp. 918-931, 2009. 


\section{Appendix A. The detailed values for the model shown in Fig. 12 equivalent to the numerical calculations in 4.2}

The parameter values for the model in Fig 12 equivalent to the numerical study (by the model shown in Fig. 13) under the assumption of eq. (5) are summarized in Table A1-A6.

Table A1. Parameter values for the SAP models for Case 1A in the 2DOF SAP model and the equivalent model

\begin{tabular}{|c|c|c|c|c|c|}
\hline \multicolumn{3}{|c|}{$\begin{array}{l}\text { 2DOF SAP model (subsystem) } \\
\text { shown in Fig. } 13\end{array}$} & \multicolumn{3}{|c|}{$\begin{array}{l}\text { Equivalent parameter values in the model } \\
\text { shown in Fig. } 12 \text { to the 2DOF SAP model }\end{array}$} \\
\hline variable & unit & value & variable & unit & value \\
\hline$m_{1}$ & $\mathrm{~kg}$ & 0.15 & $m_{11}\left(=m_{12}\right)$ & $\mathrm{kg}$ & 0.075 \\
\hline$k_{1}$ & $\mathrm{~N} / \mathrm{m}$ & $8.4 \times 10^{3}$ & $k_{11}\left(=k_{12}\right)$ & $\mathrm{N} / \mathrm{m}$ & $4.2 \times 10^{3}$ \\
\hline$c_{1}$ & $\mathrm{Ns} / \mathrm{m}$ & 3.55 & $c_{11}\left(=c_{12}\right)$ & $\mathrm{Ns} / \mathrm{m}$ & 1.77 \\
\hline$\zeta_{1}$ & - & 0.05 & & & \\
\hline$m_{2}$ & $\mathrm{~kg}$ & 0.15 & $m_{22}\left(=2 m_{21}=2 m_{23}\right)$ & $\mathrm{kg}$ & 0.075 \\
\hline$k_{2}$ & $\mathrm{~N} / \mathrm{m}$ & $25.2 \times 10^{3}$ & $k_{21}\left(=k_{22}=k_{23}\right)$ & $\mathrm{N} / \mathrm{m}$ & $8.4 \times 10^{3}$ \\
\hline$c_{2}$ & $\mathrm{Ns} / \mathrm{m}$ & 7.53 & $c_{21}\left(=c_{22}=c_{23}\right)$ & $\mathrm{Ns} / \mathrm{m}$ & 1.67 \\
\hline$\zeta_{2}$ & - & 0.05 & $\theta_{21}\left(=\theta_{22}=\theta_{23}\right)$ & deg. & 60 \\
\hline Total additional mass & $\mathrm{kg}$ & 0.3 & Total additional mass & $\mathrm{kg}$ & 0.3 \\
\hline \multicolumn{3}{|c|}{$\begin{array}{l}\text { Natural frequencies of the } \quad 25.506,96.327 \mathrm{~Hz} \\
\text { 2DOF subsystem }\end{array}$} & & & \\
\hline \multicolumn{2}{|c|}{ Numerical result } & $\begin{array}{l}\text { Fig. } 14-16 \\
\text { (blue line) }\end{array}$ & & & \\
\hline
\end{tabular}

Table A2. Parameter values for the SAP models for Case 1B in the 2DOF SAP model and the equivalent model.

\begin{tabular}{|c|c|c|c|c|c|}
\hline \multicolumn{3}{|c|}{$\begin{array}{l}\text { 2DOF SAP model (subsystem) } \\
\text { shown in Fig. } 13\end{array}$} & \multicolumn{3}{|c|}{$\begin{array}{l}\text { Equivalent parameter values in the model } \\
\text { shown in Fig. } 12 \text { to the 2DOF SAP model }\end{array}$} \\
\hline variable & unit & value & variable & unit & value \\
\hline$m_{1}$ & $\mathrm{~kg}$ & 0.21 & $m_{11}\left(=m_{12}\right)$ & $\mathrm{kg}$ & 0.105 \\
\hline$k_{1}$ & $\mathrm{~N} / \mathrm{m}$ & $8.4 \times 10^{3}$ & $k_{11}\left(=k_{12}\right)$ & $\mathrm{N} / \mathrm{m}$ & $4.2 \times 10^{3}$ \\
\hline$c_{1}$ & $\mathrm{Ns} / \mathrm{m}$ & 4.20 & $c_{11}\left(=c_{12}\right)$ & $\mathrm{Ns} / \mathrm{m}$ & 2.10 \\
\hline$\zeta_{1}$ & - & 0.05 & & & \\
\hline$m_{2}$ & $\mathrm{~kg}$ & 0.21 & $m_{22}\left(=2 m_{21}=2 m_{23}\right)$ & $\mathrm{kg}$ & 0.105 \\
\hline$k_{2}$ & $\mathrm{~N} / \mathrm{m}$ & $25.2 \times 10^{3}$ & $k_{21}\left(=k_{22}=k_{23}\right)$ & $\mathrm{N} / \mathrm{m}$ & $8.4 \times 10^{3}$ \\
\hline$c_{2}$ & $\mathrm{Ns} / \mathrm{m}$ & 8.91 & $c_{21}\left(=c_{22}=c_{23}\right)$ & $\mathrm{Ns} / \mathrm{m}$ & 1.98 \\
\hline$\zeta_{2}$ & - & 0.05 & $\theta_{21}\left(=\theta_{22}=\theta_{23}\right)$ & deg. & 60 \\
\hline Total additional mass & $\mathrm{kg}$ & 0.42 & Total additional mass & $\mathrm{kg}$ & 0.42 \\
\hline \multicolumn{3}{|c|}{$\begin{array}{l}\text { Natural frequencies of the } \\
\text { 2DOF subsystem }\end{array}$} & & & \\
\hline \multicolumn{2}{|c|}{ Numerical result } & $\begin{array}{c}\text { Fig. } 14 \\
\text { (red line) }\end{array}$ & & & \\
\hline
\end{tabular}

Table A3. Parameters values for the SAP models for Case 1B in the 3DOF SAP model and the equivalent model: in case with nearly-uniform distributions of $m_{p q}$ and $k_{p q}$.

\begin{tabular}{|c|c|c|c|c|c|}
\hline \multicolumn{3}{|c|}{$\begin{array}{l}\text { 3DOF SAP model (subsystem) } \\
\text { shown in Fig. } 13\end{array}$} & \multicolumn{3}{|c|}{$\begin{array}{l}\text { Equivalent parameter values in the model } \\
\text { shown in Fig. } 12 \text { to the 3DOF SAP model }\end{array}$} \\
\hline variable & unit & value & variable & unit & value \\
\hline$m_{1}$ & $\mathrm{~kg}$ & 0.15 & $m_{11}\left(=m_{12}\right)$ & $\mathrm{kg}$ & 0.075 \\
\hline$k_{1}$ & $\mathrm{~N} / \mathrm{m}$ & $8.4 \times 10^{3}$ & $k_{11}\left(=k_{12}\right)$ & $\mathrm{N} / \mathrm{m}$ & $4.2 \times 10^{3}$ \\
\hline$c_{1}$ & $\mathrm{Ns} / \mathrm{m}$ & 4.20 & $c_{11}\left(=c_{12}\right)$ & $\mathrm{Ns} / \mathrm{m}$ & 2.10 \\
\hline$\zeta_{1}$ & - & 0.05 & & & \\
\hline$m_{2}$ & $\mathrm{~kg}$ & 0.15 & $m_{22}\left(=2 m_{21}=2 m_{23}\right)$ & $\mathrm{kg}$ & 0.075 \\
\hline$k_{2}$ & $\mathrm{~N} / \mathrm{m}$ & $12.6 \times 10^{3}$ & $k_{21}\left(=k_{22}=k_{23}\right)$ & $\mathrm{N} / \mathrm{m}$ & $4.2 \times 10^{3}$ \\
\hline$c_{2}$ & $\mathrm{Ns} / \mathrm{m}$ & 5.32 & $c_{21}\left(=c_{22}=c_{23}\right)$ & $\mathrm{Ns} / \mathrm{m}$ & 1.77 \\
\hline$\zeta_{2}$ & - & 0.05 & $\theta_{21}\left(=\theta_{22}=\theta_{23}\right)$ & deg. & 60 \\
\hline$m_{3}$ & $\mathrm{~kg}$ & 0.12 & $m_{31}\left(=m_{32}\right)$ & $\mathrm{kg}$ & 0.06 \\
\hline$k_{3}$ & $\mathrm{~N} / \mathrm{m}$ & $12.6 \times 10^{3}$ & $k_{31}\left(=k_{32}\right)$ & $\mathrm{N} / \mathrm{m}$ & $4.2 \times 10^{3}$ \\
\hline$c_{3}$ & $\mathrm{Ns} / \mathrm{m}$ & 4.76 & $c_{31}\left(=c_{32}\right)$ & $\mathrm{Ns} / \mathrm{m}$ & 1.59 \\
\hline$\zeta_{3}$ & - & 0.05 & $\theta_{31}\left(=\theta_{32}\right)$ & deg. & 60 \\
\hline Total additional mass & $\mathrm{kg}$ & 0.42 & Total additional mass & $\mathrm{kg}$ & 0.42 \\
\hline \multicolumn{3}{|c|}{$\begin{array}{ll}\begin{array}{l}\text { Natural frequencies of the } \\
\text { 3DOF subsystem }\end{array} & \begin{array}{l}19.117,56.326 \\
83.207 \mathrm{~Hz}\end{array} \\
\end{array}$} & & & \\
\hline \multicolumn{2}{|c|}{ Numerical result } & $\begin{array}{l}\begin{array}{c}\text { Fig. } 15 \\
\text { (red line) }\end{array} \\
\end{array}$ & & & \\
\hline
\end{tabular}

Table A4. Calculation parameters used in the SAP models for Case 1B and $3 \mathrm{~A}$ in the $3 \mathrm{DOF}$ SAP model and the equivalent model: in case with un-uniform distributions of $m_{p q}$ and $k_{p q}$

\begin{tabular}{|c|c|c|c|c|c|}
\hline \multicolumn{3}{|c|}{$\begin{array}{l}\text { 3DOF SAP model (subsystem) } \\
\text { shown in Fig. } 13\end{array}$} & \multicolumn{3}{|c|}{$\begin{array}{l}\text { Equivalent parameter values in the model } \\
\text { shown in Fig. } 12 \text { to the } 3 \text { DOF SAP model }\end{array}$} \\
\hline variable & unit & value & variable & unit & value \\
\hline$m_{1}$ & $\mathrm{~kg}$ & 0.195 & $m_{11}\left(=m_{12}\right)$ & $\mathrm{kg}$ & 0.0975 \\
\hline$k_{1}$ & $\mathrm{~N} / \mathrm{m}$ & $8.4 \times 10^{3}$ & $k_{11}\left(=k_{12}\right)$ & $\mathrm{N} / \mathrm{m}$ & $4.2 \times 10^{3}$ \\
\hline$c_{1}$ & $\mathrm{Ns} / \mathrm{m}$ & 4.05 & $c_{11}\left(=c_{12}\right)$ & $\mathrm{Ns} / \mathrm{m}$ & 2.10 \\
\hline$\zeta_{1}$ & - & 0.05 & & & \\
\hline$m_{2}$ & $\mathrm{~kg}$ & 0.195 & $m_{22}\left(=2 m_{21}=2 m_{23}\right)$ & $\mathrm{kg}$ & 0.0975 \\
\hline$k_{2}$ & $\mathrm{~N} / \mathrm{m}$ & $12.6 \times 10^{3}$ & $k_{21}\left(=k_{22}=k_{23}\right)$ & $\mathrm{N} / \mathrm{m}$ & $4.2 \times 10^{3}$ \\
\hline$c_{2}$ & $\mathrm{Ns} / \mathrm{m}$ & 8.59 & $c_{21}\left(=c_{22}=c_{23}\right)$ & $\mathrm{Ns} / \mathrm{m}$ & 2.86 \\
\hline$\zeta_{2}$ & - & 0.05 & $\theta_{21}\left(=\theta_{22}=\theta_{23}\right)$ & deg. & 60 \\
\hline$m_{3}$ & $\mathrm{~kg}$ & 0.03 & $m_{31}\left(=m_{32}\right)$ & $\mathrm{kg}$ & 0.015 \\
\hline$k_{3}$ & $\mathrm{~N} / \mathrm{m}$ & 540 & $k_{31}\left(=k_{32}\right)$ & $\mathrm{N} / \mathrm{m}$ & 180 \\
\hline$c_{3}$ & $\mathrm{Ns} / \mathrm{m}$ & 0.493 & $c_{31}\left(=c_{32}\right)$ & $\mathrm{Ns} / \mathrm{m}$ & 0.164 \\
\hline$\zeta_{3}$ & - & 0.05 & $\theta_{31}\left(=\theta_{32}\right)$ & deg. & 60 \\
\hline Total additional mass & $\mathrm{kg}$ & 0.42 & Total additional mass & $\mathrm{kg}$ & 0.42 \\
\hline \multicolumn{2}{|c|}{$\begin{array}{l}\text { Natural frequencies of the } \\
\text { 3DOF subsystem }\end{array}$} & $\begin{array}{l}18.838,25.301 \\
84.671 \mathrm{~Hz}\end{array}$ & & & \\
\hline \multicolumn{2}{|c|}{ Numerical result } & $\begin{array}{l}\text { Fig. } 16 \text { (red line) } \\
\text { Fig. } 17 \text { (blue line) }\end{array}$ & & & \\
\hline
\end{tabular}

Table A5. Calculation parameters used in the SAP models for Case 3B in the 3DOF SAP model and the equivalent model: in case with ununiform distributions of $m_{p q}$ and $k_{p q}$.

\begin{tabular}{|c|c|c|c|c|c|}
\hline \multicolumn{3}{|c|}{$\begin{array}{l}\text { 3DOF SAP model (subsystem) } \\
\text { shown in Fig. } 13\end{array}$} & \multicolumn{3}{|c|}{$\begin{array}{l}\text { Equivalent parameter values in the model } \\
\text { shown in Fig. } 12 \text { to the } 3 \text { DOF SAP model }\end{array}$} \\
\hline variable & unit & value & variable & unit & value \\
\hline$m_{1}$ & $\mathrm{~kg}$ & 0.195 & $m_{11}\left(=m_{12}\right)$ & $\mathrm{kg}$ & 0.0975 \\
\hline$k_{1}$ & $\mathrm{~N} / \mathrm{m}$ & $8.4 \times 10^{3}$ & $k_{11}\left(=k_{12}\right)$ & $\mathrm{N} / \mathrm{m}$ & $4.2 \times 10^{3}$ \\
\hline$c_{1}$ & $\mathrm{Ns} / \mathrm{m}$ & 10.12 & $c_{11}\left(=c_{12}\right)$ & $\mathrm{Ns} / \mathrm{m}$ & 5.06 \\
\hline$\zeta_{1}$ & - & 0.125 & & & \\
\hline$m_{2}$ & $\mathrm{~kg}$ & 0.195 & $m_{22}\left(=2 m_{21}=2 m_{23}\right)$ & $\mathrm{kg}$ & 0.0975 \\
\hline$k_{2}$ & $\mathrm{~N} / \mathrm{m}$ & $12.6 \times 10^{3}$ & $k_{21}\left(=k_{22}=k_{23}\right)$ & $\mathrm{N} / \mathrm{m}$ & $4.2 \times 10^{3}$ \\
\hline$c_{2}$ & $\mathrm{Ns} / \mathrm{m}$ & 8.59 & $c_{21}\left(=c_{22}=c_{23}\right)$ & $\mathrm{Ns} / \mathrm{m}$ & 2.86 \\
\hline$\zeta_{2}$ & - & 0.05 & $\theta_{21}\left(=\theta_{22}=\theta_{23}\right)$ & deg. & 60 \\
\hline$m_{3}$ & $\mathrm{~kg}$ & 0.03 & $m_{31}\left(=m_{32}\right)$ & $\mathrm{kg}$ & 0.015 \\
\hline$k_{3}$ & $\mathrm{~N} / \mathrm{m}$ & 5400 & $k_{31}\left(=k_{32}\right)$ & $\mathrm{N} / \mathrm{m}$ & 1800 \\
\hline$c_{3}$ & $\mathrm{Ns} / \mathrm{m}$ & 1.56 & $c_{31}\left(=c_{32}\right)$ & $\mathrm{Ns} / \mathrm{m}$ & 0.52 \\
\hline$\zeta_{3}$ & - & 0.05 & $\theta_{31}\left(=\theta_{32}\right)$ & deg. & 60 \\
\hline Total additional mass & $\mathrm{kg}$ & 0.42 & Total additional mass & $\mathrm{kg}$ & 0.42 \\
\hline $\begin{array}{l}\text { Natural frequencies o } \\
\text { 3DOF subsystem }\end{array}$ & the & $\begin{array}{l}9,67.189, \\
8 \mathrm{~Hz}\end{array}$ & & & \\
\hline Numerical res & & $\begin{array}{c}\text { Fig. } 17 \\
\text { (red line) }\end{array}$ & & & \\
\hline
\end{tabular}

Table A6. Calculation parameters used in the SAP models for Case 3C in the 3DOF SAP model and the equivalent model: in case with un-uniform distributions of $m_{p q}$ and $k_{p q}$.

\begin{tabular}{|c|c|c|c|c|c|}
\hline \multicolumn{3}{|c|}{$\begin{array}{l}\text { 3DOF SAP model (subsystem) } \\
\text { shown in Fig. } 13\end{array}$} & \multicolumn{3}{|c|}{$\begin{array}{l}\text { Equivalent parameter values in the model } \\
\text { shown in Fig. } 12 \text { to the 3DOF SAP model }\end{array}$} \\
\hline variable & unit & value & variable & unit & value \\
\hline$m_{1}$ & $\mathrm{~kg}$ & 0.195 & $m_{11}\left(=m_{12}\right)$ & $\mathrm{kg}$ & 0.0975 \\
\hline$k_{1}$ & $\mathrm{~N} / \mathrm{m}$ & $12.0 \times 10^{3}$ & $k_{11}\left(=k_{12}\right)$ & $\mathrm{N} / \mathrm{m}$ & $6.0 \times 10^{3}$ \\
\hline$c_{1}$ & $\mathrm{Ns} / \mathrm{m}$ & 12.09 & $c_{11}\left(=c_{12}\right)$ & $\mathrm{Ns} / \mathrm{m}$ & 6.05 \\
\hline$\zeta_{1}$ & - & 0.125 & & & \\
\hline$m_{2}$ & $\mathrm{~kg}$ & 0.195 & $m_{22}\left(=2 m_{21}=2 m_{23}\right)$ & $\mathrm{kg}$ & 0.0975 \\
\hline$k_{2}$ & $\mathrm{~N} / \mathrm{m}$ & $25.2 \times 10^{4}$ & $k_{21}\left(=k_{22}=k_{23}\right)$ & $\mathrm{N} / \mathrm{m}$ & $8.4 \times 10^{4}$ \\
\hline$c_{2}$ & $\mathrm{Ns} / \mathrm{m}$ & 27.15 & $c_{21}\left(=c_{22}=c_{23}\right)$ & $\mathrm{Ns} / \mathrm{m}$ & 9.05 \\
\hline$\zeta_{2}$ & - & 0.05 & $\theta_{21}\left(=\theta_{22}=\theta_{23}\right)$ & deg. & 60 \\
\hline$m_{3}$ & $\mathrm{~kg}$ & 0.03 & $m_{31}\left(=m_{32}\right)$ & $\mathrm{kg}$ & 0.015 \\
\hline$k_{3}$ & $\mathrm{~N} / \mathrm{m}$ & 5400 & $k_{31}\left(=k_{32}\right)$ & $\mathrm{N} / \mathrm{m}$ & 1800 \\
\hline$c_{3}$ & $\mathrm{Ns} / \mathrm{m}$ & 1.56 & $c_{31}\left(=c_{32}\right)$ & $\mathrm{Ns} / \mathrm{m}$ & 0.52 \\
\hline$\zeta_{3}$ & - & 0.05 & $\theta_{31}\left(=\theta_{32}\right)$ & deg. & 60 \\
\hline Total additional mass & $\mathrm{kg}$ & 0.42 & Total additional mass & $\mathrm{kg}$ & 0.42 \\
\hline $\begin{array}{l}\text { Natural frequencies o } \\
\text { 3DOF subsystem }\end{array}$ & the & $\begin{array}{l}\text { 81, } 70.405, \\
.123 \mathrm{~Hz}\end{array}$ & & & \\
\hline Numerical res & & $\begin{array}{c}\text { Fig. } 17 \\
\text { (green line) }\end{array}$ & & & \\
\hline
\end{tabular}

